\title{
Investment Risk and Returns: The Relationship Between A Stock and An Index Using the Modern Portfolio Theory
}

\author{
Prof Tan ZongMing Koomson Prince* Dr. Ding Guoping \\ School of Finance and Applied Economics, Jiangsu University 301 Xuefu Road, China
}

\begin{abstract}
The aim of this report is to examine investment risk and returns by looking at the relationship between a stock and an index using the Markowitz Modern Portfolio theory. Monthly Data on IBM and Dow Jones were obtained from yahoo finance for the period 1995 to 2015. A linear regression was utilized to analyze the relationship between the Dow Jones index and the IBM stock returns. The results revealed that there is a positive relationship between IBM stock returns and the Dow Jones index. In their decision making, investors and policy makers are, recommended to additionally consider the micro and macro demand and supply forces that could possibly influence ROI. In other to avoid or reduce risk.
\end{abstract}

Keywords: Portfolio, investment, risk, index, relationship, stocks

\section{INTRODUCTION}

This article aims to demonstrate, in practice, the application of Markowitz's modern portfolio theory as an important tool for making investment decisions. Markowitz won the Nobel Prize in 1990 for his enormous contribution in the field of investment and finance. Its Role as Portfolio Selection: Rational Diversification (1952) His paper "portfolio Selection: efficient Diversification (1959) has Influenced Many Lives in Making Investment Decisions.

The Markowitz theory of today is what has come to be regarded as the "Theory of Modern Portfolio" (MPT). This theory allows potential investors to analyze portfolio risks and returns before making any attempt to select one.

In 1964, William Sharpe, built another theory, which has its justification from Markowitz MPT, William Sharpe's current theory is what is known by both investors and the academic world as the asset valuation model.

Investors are very keen to know the returns they will have on their investment, this can be said to be one of the main reasons why people invest in diverse portfolios. In other for this returns to be optimized hence reduce risk implies investors to diversify their investment. Holding multiple portfolios alone isn't prudent enough to justify one's ability to maximize return on investment.

Investors are very interested in learning about the benefits they will have on their investment, this can be said to be one of the main reasons why people invest in different portfolios. In other to reduce the risks involved on portfolio selection investors diversify their investments Holding multiple portfolios alone isn't prudent enough to justify one's ability to maximize return on investment

The world of financial investment is a very risky and volatile field to venture as such a careful and critical investment risk and returns analysis is required to avoid any shocks.

It is based on the above highlighted that this paper seeks to aid all investment and financial stake holders to acquire the knowledge and dealings of the financial market. This paper will focus on the Modern Portfolio theory as an efficient investment decision making analysis tool. Specifically this paper will discuss specific issues such as the review and framework of the MPT, risk and returns, expected returns, risk measurement and volatility and well as risk diversification.

It is based on the above highlights that this document aims to assist all investment owners and financial stakeholders to acquire knowledge and dealings of financial markets. This paper will focus on the portfolio theory as a tool for the analysis of efficient investment decision. In particularly, this paper will address specific topics such as the revision and framework of the MPT, risk and returns, risk measurement and volatility, as well as risk diversification.

This paper will focus on using the monthly returns of IBM stock from 1996 to 2015 to analyse Markowitz MPT using the Dow jones as the benchmark.

It is the aim of this paper to contribute to the pool of knowledge existing in investment decision making as well as academia on the above subject.

The paper's emphasis is on risk and returns focusing on the relationship between the monthly stocks returns of Dow Jones index and IBM using a liner regression model. It analyses the modern portfolio theory as an investment tool. It avoids the complex mathematical calculations by using simple techniques to analyse the MPT.

Data gathered included the monthly adjusted stock prices for the Dow Jones Index and the IBM stocks drawn from S\&P500 from 2015 to January 1996. The computations were done using Microsoft excel. 


\section{A REVIEW OF RELATED LITERATURE}

The investment decision-making process is the ability to make appropriate decisions and be guided by the various theories of portfolio investments. The most important aspect of the Markowitz model was its description of the impact on portfolio diversification by the number of securities within a portfolio and covariance relationships (Megginson, 1996). In 1958, James Tobin in the evaluation of the conditions of economic studies proposed the "efficient frontier" and the ideas of the "Market Line Capital" built on MPT. His model proposed that investors, regardless of their level of risk tolerance, hold equity portfolios in the same portion, as long as the expectations remain the same with respect to the future (1996 Megginson quoting Tobin, 1958). Tobin concluded that the investment portfolios of these investors only vary in their relative proportions of stocks and bonds.

There are basically two approaches to managing investments:

2.1 The Passive investment approach:

This approach is based on the belief that markets are efficient, market returns cannot be outdone repeatedly overtime and low cost investments held for a long term will provide the best returns.

\subsection{Active asset management:}

- This approach is based on the belief that a specific style of management or analysis can produce returns that beat the market.

The active approach seeks to take advantage of inefficiencies in the market and is typically accompanied by higher-than-average costs (for analysts and managers who must spend time to seek out these inefficiencies).

- Market timing is an extreme example of active asset management. It is based on the belief that it's possible to anticipate the movement of markets based on factors such as economic conditions, interest rate trends or technical indicators. Many investors, particularly academics, believe it is impossible to correctly time the market on a consistent basis.

\section{THE MODERN PORTFOLIO THEORY (MPT)}

Harry Markowitz in 1952 published an article "Portfolio Selection" in the Journal of Finance, he developed a hypothesis which is an investment theory based on the concept that the risk-averse investors can develop their portfolios to maximize expected returns based on a particular market, Level of risk, emphasizing that risk is an inherent aspect of higher premiums. MPT is an investment framework for building and selection of a portfolio based on performance maximizing and minimizing investment risks (Fabozzi, Gupta and Markowitz, 2002).

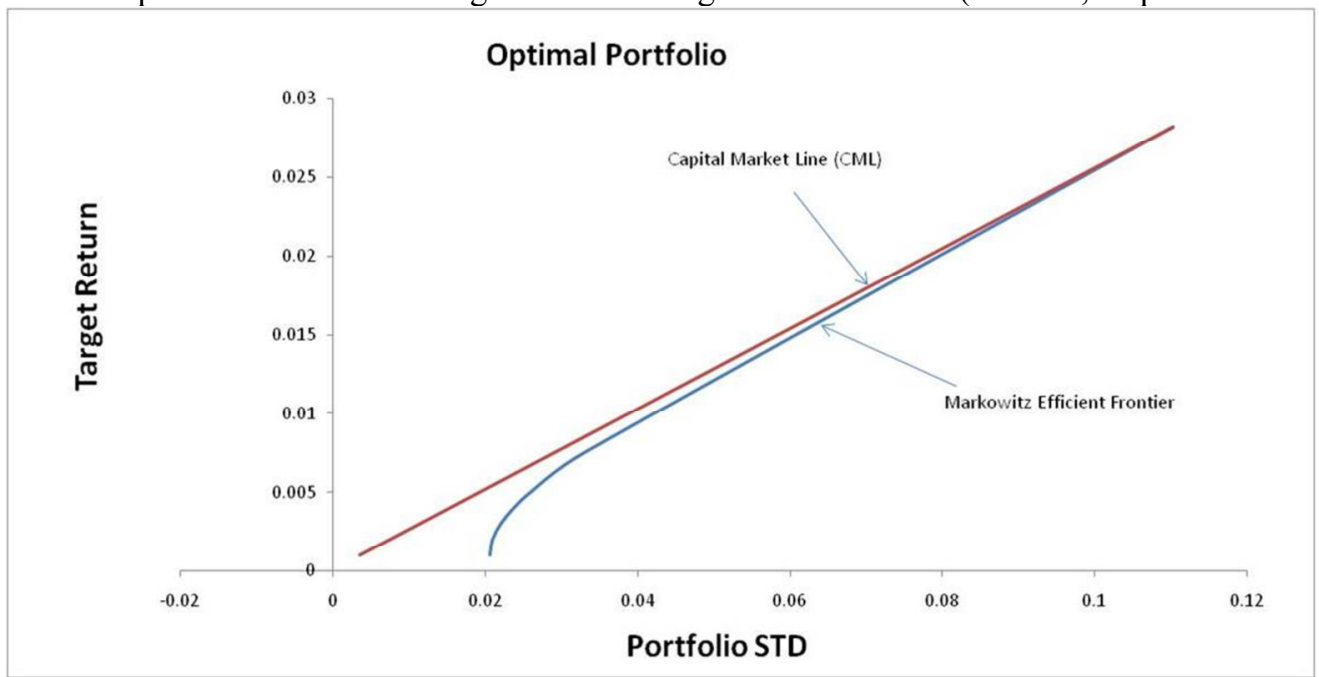

Fig 1. Markowitz Modern Portfolio Theory.(Source:.......)

\section{THE EFFICIENT FRONTIER}

In order to weigh investment options, Markowitz propounded a system to describe each investment or each class of asset with mathematical formulas using unsystematic risk statistics. He then applied that to the portfolios that has the investment options. He considered the expected rate of return and the expected volatility for each investment. He named this risk and reward equation "The Efficient Frontier". Fig 2 is a typical example of what the efficient frontier equation looks like when plotted which has an aim of maximizing returns while minimizing volatility. To evaluate investments, Markowitz proposed a system which describes any investment or any asset 
class with mathematical formulas with the use of unsystematic risks. Then he applied this to portfolio investment opportunities, he carefully considered the expected return and expected volatility for each investment. He called this equation risk and reward "Efficient Frontier". Fig 2 below is typical of what appears to be a comparison of the efficient frontier when plotted with the aim of maximizing returns and reducing volatility.

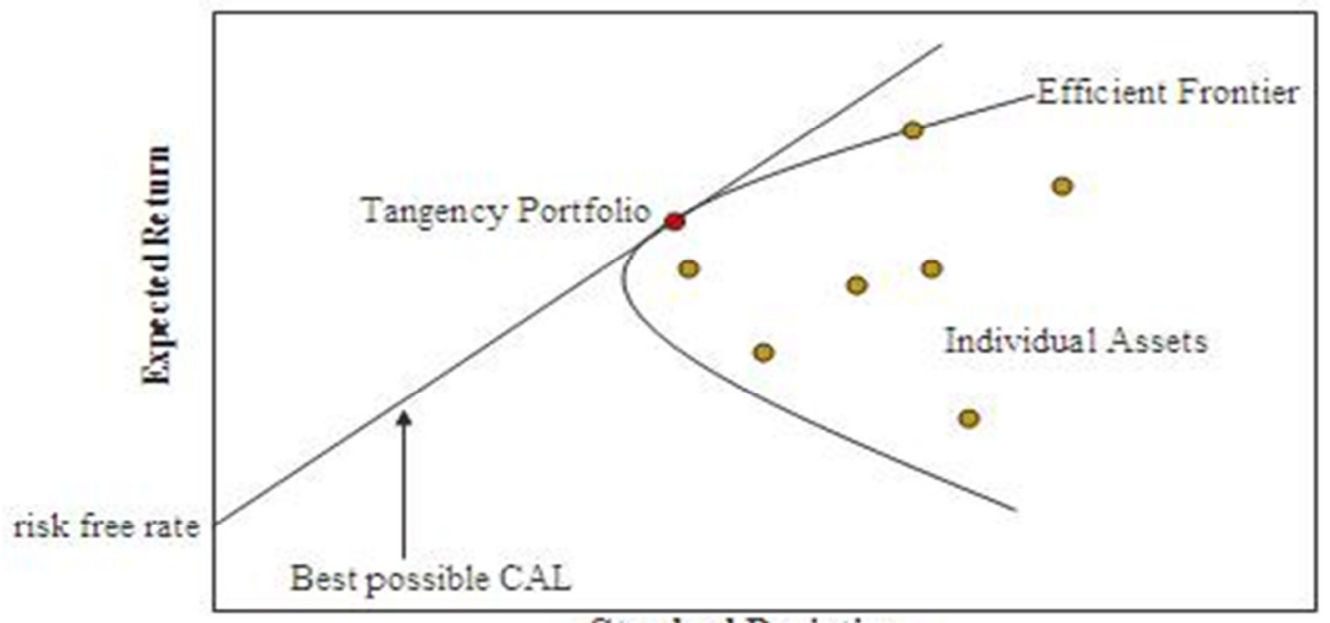

Standard Deviation

Fig 2 The Efficient Frontier (retrieved from Wikipedia)

Portfolios along the efficient frontier should have higher returns on average, for the level of risk the portfolio assumes. From the graph it's seen that a typical efficient frontier line starts with lower expected risk and returns as more and more the returns of an asset increase the greater the risk. Which implies that the greater the returns of a particular stock the greater the risk thereof. There is a limit to returns on investment as such it is seen from the graph that the efficient frontier curve flattens as it goes higher. Investing is a trade-off between risk and expected returns, this concept is true with what (Taleb, 2007) stated, generally, assets with higher expected risk are riskier. The MPT provides a means to properly select a portfolio with the highest possible expected return, thus the MPT proposes a trade-off between the selection of risk with higher expected return with lower risk and other risky portfolios.

A greater emphasis of the theory is the quantification of the relationship between risk and returns and the philosophy that investors must be compensated for holding risk. Portfolio theory departs from the traditional security analysis in shifting emphasis from the analyzing the characteristics of individual investments to determining the statistical relationships among the individual securities that comprise the overall portfolio (Edwin and Martins 1997)

The risk component of MPT can be measured using mathematical formulas via the concept of diversification in investment with the aim of selecting a collection of investment assets that has the lower risk than any individual asset or singular asset class. Diversification is the core concept of MPT and mainly lies on the adage of "never putting all your eggs in one basket" (fabozzi, Gupta, \& Markowitz, 2002; McClure, 2010; Veneeya, 2006).

According to the work of (Bofah, n.d.; Wecker, n.d.; Markowitz, 1952) the framework for MPT includes numerous assumptions about markets and investors, some of these assumptions are explicit, while others are implicit

Modern Portfolio Theory lies on the following conventions and fundamentals:

- For buying and selling securities there are no transaction costs. There is no spread between bidding and asking prices. No tax is paid, its only risk that plays a part in determining which securities an investor will buy.

- An investor has a chance to take any position of any size and in any security. The market liquidity is infinite and no one can move the market. So that nothing can stop the investor from taking positions of any size in any security.

- While making investment decisions the investor does not consider taxes and is indifferent towards receiving dividends or capital gains.

- Investors are generally rational and risk adverse. They are completely aware of all the risk contained in investment and actually take positions based on the risk determination demanding a higher return for accepting greater volatility.

- The risk-return relationships are viewed over the same time horizon. Both long term speculator and short term speculator share the same motivations, profit target and time horizon.

- Investors share identical views on risk measurement. All the investors are provided by information and 
their sale or purchase depends on an identical assessment of the investment and all have the same expectations from the investment. A seller will be motivated to make a sale only because another security has a level of volatility that corresponds to his desired return. A buyer will buy because this security has a level of risk that corresponds to the return he wants.

- Investors seek to control risk only by the diversification of their holdings.

- In the market all assets can be bought and sold including human capital.

- Politics and investor psychology have no influence on market.

- The risk of portfolio depends directly on the instability of returns from the given portfolio.

- An investor gives preference to the increase of utilization.

- An investor either maximizes his return for the minimum risk or maximizes his portfolio return for a given level of risk.

- Analysis is based on a single period model of investment.

According to (Iyio O, et al 2012), the theory does not really model the market. The risk, return and correlation used by MPT are based on expected values, which means that they are mathematical statements about the future.

\section{DATA AND METHOD}

\subsection{DATA}

The Data for the Dow Jones Index and the IBM stocks for the period January 1996 to 2015 was obtained from S\&P500. This study further adjusted the stock prices into monthly returns.

The Dow Jones Industrial Average (DJIA) was employed because it is undoubtedly the most cited financial barometer in the world and has become synonymous with financial markets in general. When individuals say that the market has increased or decreased by some digits, they mostly denote the Dow. On the other hand the IBM stocks were selected randomly out of the number of stocks listed under the index

\subsection{METHOD}

This study tested the risk-return relationship using the model estimated in equations 1-3

$E\left(R_{P}\right)=\sum W_{i} E\left(R_{i}\right) \ldots \ldots \ldots$

The equation 1 is further extended into

$E\left(R_{P}\right)=W_{A} E\left(R_{A}\right)+W_{B} E\left(R_{B}\right)$

$E\left(R_{P}\right)=W_{A} E\left(R_{A}\right)+\left(1-W_{A}\right) E\left(R_{B}\right)$

Where $R_{p}$ is the return on the portfolio, $R_{i}$ is the return on the asset $i$ and $W i$ is the weighing of the component asset

$\operatorname{RISK}\left(R_{i}\right)$

Risk is demonstrated whenever an investor is not sure of his return on investment. (Bofah,\& ; McClure, 2010) defined risk as a deviation from expected historical returns in a particular period. Notwithstanding, Markowitz' portfolio selection theory maintains that "the essential aspect pertaining to the risk of an asset is not the risk of each asset in isolation, but the contribution of each asset to the risk of the aggregate portfolio" (Royal Swedish Academy of Sciences, 1990). As discussed, the idea of risk generally is the possibility that actual return may vary from expected return. Investment of greater variance in terms of risk are considered very risky and vice versa.

Risk is different from uncertainty. Risk is the situation at which the tendency of expected return deviating from actual return can be quantified whereas uncertainty happens in a situation at which this condition can't be quantified or the fact and figure regarding investment is not readily available.

Low levels of uncertainty are accompanied with low probable returns, whereas high levels of uncertainty are associated with high probable returns. With regards to the risk-return tradeoff, money invested can produce greater benefits only when the investor is willing to accept the possibility of losses. Hence investments with high risk has a high probability of ROI and vice versa

\section{RISK MEASUREMENT AND VOLATITY: BETA COEFFICIENT}

MPT, however, do not define risk as the probability of loss, but as the volatility, which is defined by statistical measures of variations, such as standard deviation and beta. The greater the standard deviation or beta, the greater the risk, according to the theory.

Beta measures risk of an asset relative to the market risk. The market risk is measured using the fluctuations of the market benchmark (market Index). Shares with $\beta$ factor is more than 1 are considered less risky. One must note that $\beta$ is a measure of systematic risk which cannot be diversified.

$\beta=\frac{\text { Covariance }\left(\mathrm{r}_{\mathrm{s}}, \mathrm{r}_{\mathrm{b}}\right)}{\text { Variance }\left(\mathrm{r}_{\mathrm{b}}\right)}$

thus, 


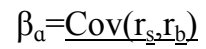

$\operatorname{Var}\left(\mathrm{r}_{\mathrm{b}}\right)$ where $\mathrm{rs}$ is the return on the stock and $\mathrm{r}_{\mathrm{b}}$ is the return on a benchmark index .

Beta helps us to understand the idea of passive and active risk. Fig 3 shows a time series of each returns labeled "+" for a particular portfolio $\mathrm{R}(\mathrm{p})$ against the market return $\mathrm{R}(\mathrm{m})$. The returns are cash adjusted, the point fit through the data point at which the $\mathrm{x}$ and $\mathrm{y}$ axes intersect is the cash - equivalent return. Drawing a line of best fit through the data points allows us to quantify the beta, which is referred to as alpha.

Beta helps us to understand the concept of passive and active risk. Fig 3 shows a time sequence returns labeled "+" for a specific portfolio $\mathrm{R}(\mathrm{p})$ against market returns yields $\mathrm{R}(\mathrm{m})$. The returns are cash adjusted, the point fit through the data point at which the $\mathrm{x}$ and $\mathrm{y}$ axes intersect is the cash - equivalent return. Drawing a line of best fit through the data points allows us to quantify the beta, which is referred to as alpha

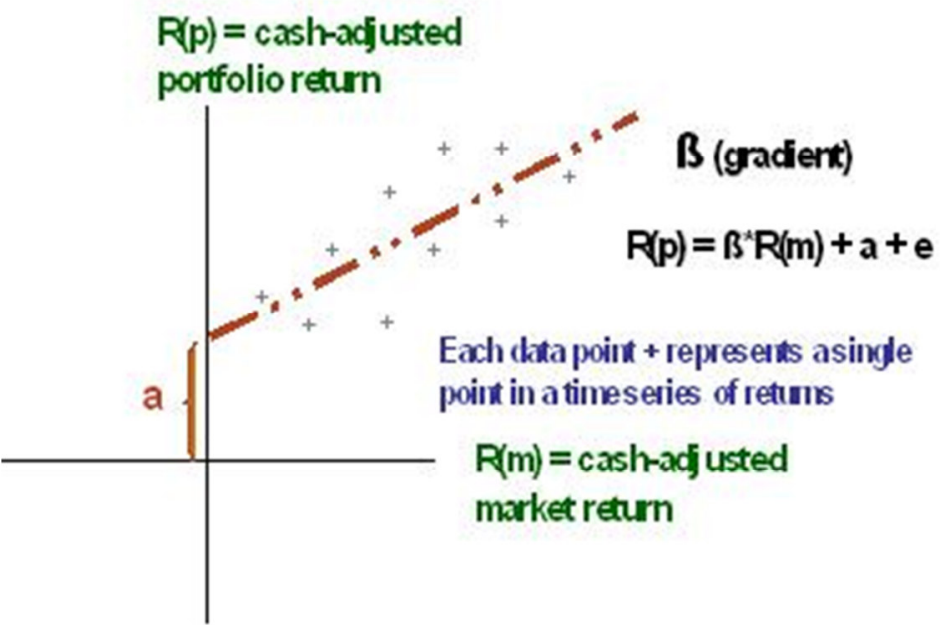

Fig 3 Time Series Beta

The slope of the line is referred to as the beta.

A slope of 1.0 means that for each unit of market profitability increase, the performance of the portfolio increases by one. A manager using a passive management strategy may be tempted to increase portfolio performance by assuming more market risk (ie, a beta greater than 1), or alternatively, decreasing portfolio risk through Reducing the beta portfolio of less than 1. Essentially, beta expresses the fundamental balance between minimizing risk and maximizing profitability.

\section{RESULTS AND DISCUSSION}

\begin{tabular}{|c|c|c|c|c|}
\hline Date & $\begin{array}{l}\text { PRICE } \\
\text { IBM }\end{array}$ & $\begin{array}{l}\text { PRICE } \\
\text { DOW J }\end{array}$ & $\begin{array}{l}\text { RETURN } \\
\text { IBM }\end{array}$ & $\begin{array}{r}\text { RETURN. } \\
\text { DOW J }\end{array}$ \\
\hline $01 / 12 / 2015$ & 134.9264 & 17425.03 & $-1.70 \%$ & $-1.70 \%$ \\
\hline $02 / 11 / 2015$ & 136.6911 & 17719.92 & $0.30 \%$ & $0.30 \%$ \\
\hline $01 / 10 / 2015$ & 136.062 & 17663.54 & $8.50 \%$ & $8.50 \%$ \\
\hline $01 / 09 / 2015$ & 140.8117 & 16284.7 & $-1.50 \%$ & $-1.50 \%$ \\
\hline $03 / 08 / 2015$ & 143.6479 & 16528.03 & $-6.60 \%$ & $-6.60 \%$ \\
\hline 01/07/2015 & 156.0481 & 17689.86 & $0.40 \%$ & $0.40 \%$ \\
\hline $01 / 06 / 2015$ & 156.6935 & 17619.51 & $-2.20 \%$ & $-2.20 \%$ \\
\hline $01 / 05 / 2015$ & 163.4271 & 18010.68 & $1.00 \%$ & $1.00 \%$ \\
\hline $01 / 04 / 2015$ & 163.7676 & 17840.52 & $0.40 \%$ & $0.40 \%$ \\
\hline $02 / 03 / 2015$ & 153.4514 & 17776.12 & $-2.00 \%$ & $-2.00 \%$ \\
\hline $02 / 02 / 2015$ & 154.8282 & 18132.7 & $5.60 \%$ & $5.60 \%$ \\
\hline $02 / 01 / 2015$ & 145.5561 & 17164.95 & $-3.70 \%$ & $-3.70 \%$ \\
\hline $01 / 12 / 2014$ & 152.3255 & 17823.07 & $0.00 \%$ & $0.00 \%$ \\
\hline 03/11/2014 & 153.968 & 17828.24 & $2.50 \%$ & $2.50 \%$ \\
\hline $01 / 10 / 2014$ & 155.0242 & 17390.52 & $2.00 \%$ & $2.00 \%$ \\
\hline $02 / 09 / 2014$ & 179.004 & 17042.9 & $-0.30 \%$ & $-0.30 \%$ \\
\hline
\end{tabular}




\begin{tabular}{|c|c|c|c|c|}
\hline Date & $\begin{array}{l}\text { PRICE } \\
\text { IBM }\end{array}$ & $\begin{array}{l}\text { PRICE } \\
\text { DOW J }\end{array}$ & $\begin{array}{l}\text { RETURN } \\
\text { IBM }\end{array}$ & $\begin{array}{r}\text { RETURN. } \\
\text { DOW J }\end{array}$ \\
\hline $01 / 08 / 2014$ & 181.3331 & 17098.45 & $3.20 \%$ & $3.20 \%$ \\
\hline $01 / 07 / 2014$ & 179.6764 & 16563.3 & $-1.60 \%$ & $-1.60 \%$ \\
\hline $02 / 06 / 2014$ & 169.9272 & 16826.6 & $0.70 \%$ & $0.70 \%$ \\
\hline $01 / 05 / 2014$ & 172.8238 & 16717.17 & $0.80 \%$ & $0.80 \%$ \\
\hline $01 / 04 / 2014$ & 183.1099 & 16580.84 & $0.70 \%$ & $0.70 \%$ \\
\hline $03 / 03 / 2014$ & 179.4006 & 16457.66 & $0.80 \%$ & $0.80 \%$ \\
\hline $03 / 02 / 2014$ & 172.5783 & 16321.71 & $4.00 \%$ & $4.00 \%$ \\
\hline $02 / 01 / 2014$ & 163.7679 & 15698.85 & $-5.30 \%$ & $-5.30 \%$ \\
\hline $02 / 12 / 2013$ & 173.862 & 16576.66 & $3.00 \%$ & $3.00 \%$ \\
\hline $01 / 11 / 2013$ & 166.5486 & 16086.41 & $3.50 \%$ & $3.50 \%$ \\
\hline $01 / 10 / 2013$ & 165.2257 & 15545.75 & $2.80 \%$ & $2.80 \%$ \\
\hline $03 / 09 / 2013$ & 170.7298 & 15129.67 & $2.20 \%$ & $2.20 \%$ \\
\hline $01 / 08 / 2013$ & 168.0469 & 14810.31 & $-4.40 \%$ & $-4.40 \%$ \\
\hline $01 / 07 / 2013$ & 178.9259 & 15499.54 & $4.00 \%$ & $4.00 \%$ \\
\hline $03 / 06 / 2013$ & 175.3206 & 14909.6 & $-1.40 \%$ & $-1.40 \%$ \\
\hline $01 / 05 / 2013$ & 190.8336 & 15115.57 & $1.90 \%$ & $1.90 \%$ \\
\hline $01 / 04 / 2013$ & 184.9395 & 14839.8 & $1.80 \%$ & $1.80 \%$ \\
\hline $01 / 03 / 2013$ & 194.7644 & 14578.54 & $3.70 \%$ & $3.70 \%$ \\
\hline $01 / 02 / 2013$ & 183.3781 & 14054.49 & $1.40 \%$ & $1.40 \%$ \\
\hline $02 / 01 / 2013$ & 184.6462 & 13860.58 & $5.80 \%$ & $5.80 \%$ \\
\hline $03 / 12 / 2012$ & 174.1714 & 13104.14 & $0.60 \%$ & $0.60 \%$ \\
\hline $01 / 11 / 2012$ & 172.8256 & 13025.58 & $-0.50 \%$ & $-0.50 \%$ \\
\hline $01 / 10 / 2012$ & 176.1103 & 13096.46 & $-2.50 \%$ & $-2.50 \%$ \\
\hline $04 / 09 / 2012$ & 187.8069 & 13437.13 & $2.60 \%$ & $2.60 \%$ \\
\hline $01 / 08 / 2012$ & 176.4 & 13090.84 & $0.60 \%$ & $0.60 \%$ \\
\hline $02 / 07 / 2012$ & 176.6686 & 13008.68 & $1.00 \%$ & $1.00 \%$ \\
\hline $01 / 06 / 2012$ & 176.3081 & 12880.09 & $3.90 \%$ & $3.90 \%$ \\
\hline $01 / 05 / 2012$ & 173.8921 & 12393.45 & $-6.20 \%$ & $-6.20 \%$ \\
\hline $02 / 04 / 2012$ & 185.8961 & 13213.63 & $0.00 \%$ & $0.00 \%$ \\
\hline $01 / 03 / 2012$ & 187.3055 & 13212.04 & $2.00 \%$ & $2.00 \%$ \\
\hline $01 / 02 / 2012$ & 176.6049 & 12952.07 & $2.50 \%$ & $2.50 \%$ \\
\hline $03 / 01 / 2012$ & 172.2267 & 12632.91 & $3.40 \%$ & $3.40 \%$ \\
\hline $01 / 12 / 2011$ & 164.4291 & 12217.56 & $1.40 \%$ & $1.40 \%$ \\
\hline $01 / 11 / 2011$ & 168.1133 & 12045.68 & $0.80 \%$ & $0.80 \%$ \\
\hline $03 / 10 / 2011$ & 164.4388 & 11955.01 & $9.50 \%$ & $9.50 \%$ \\
\hline $01 / 09 / 2011$ & 155.7461 & 10913.38 & $-6.00 \%$ & $-6.00 \%$ \\
\hline $01 / 08 / 2011$ & 153.1098 & 11613.53 & $-4.40 \%$ & $-4.40 \%$ \\
\hline $01 / 07 / 2011$ & 161.2606 & 12143.24 & $-2.20 \%$ & $-2.20 \%$ \\
\hline $01 / 06 / 2011$ & 152.1268 & 12414.34 & $-1.20 \%$ & $-1.20 \%$ \\
\hline $02 / 05 / 2011$ & 149.8034 & 12569.79 & $-1.90 \%$ & $-1.90 \%$ \\
\hline $01 / 04 / 2011$ & 150.5931 & 12810.54 & $4.00 \%$ & $4.00 \%$ \\
\hline $01 / 03 / 2011$ & 143.9631 & 12319.73 & $0.80 \%$ & $0.80 \%$ \\
\hline $01 / 02 / 2011$ & 142.9125 & 12226.34 & $2.80 \%$ & $2.80 \%$ \\
\hline
\end{tabular}




\begin{tabular}{|c|c|c|c|c|}
\hline Date & $\begin{array}{l}\text { PRICE } \\
\text { IBM }\end{array}$ & $\begin{array}{l}\text { PRICE } \\
\text { DOW J }\end{array}$ & $\begin{array}{l}\text { RETURN } \\
\text { IBM }\end{array}$ & $\begin{array}{r}\text { RETURN. } \\
\text { DOW J }\end{array}$ \\
\hline $03 / 01 / 2011$ & 142.4544 & 11891.93 & $2.70 \%$ & $2.70 \%$ \\
\hline $01 / 12 / 2010$ & 129.0531 & 11577.51 & $5.20 \%$ & $5.20 \%$ \\
\hline $01 / 11 / 2010$ & 124.3926 & 11006.02 & $-1.00 \%$ & $-1.00 \%$ \\
\hline $01 / 10 / 2010$ & 125.7158 & 11118.49 & $3.10 \%$ & $3.10 \%$ \\
\hline $01 / 09 / 2010$ & 117.4339 & 10788.05 & $7.70 \%$ & $7.70 \%$ \\
\hline $02 / 08 / 2010$ & 107.7951 & 10014.72 & $-4.30 \%$ & $-4.30 \%$ \\
\hline $01 / 07 / 2010$ & 111.8545 & 10465.94 & $7.10 \%$ & $7.10 \%$ \\
\hline $01 / 06 / 2010$ & 107.5685 & 9774.02 & $-3.60 \%$ & $-3.60 \%$ \\
\hline $03 / 05 / 2010$ & 109.1192 & 10136.63 & $-7.90 \%$ & $-7.90 \%$ \\
\hline $01 / 04 / 2010$ & 111.8041 & 11008.61 & $1.40 \%$ & $1.40 \%$ \\
\hline $01 / 03 / 2010$ & 111.1541 & 10856.63 & $5.10 \%$ & $5.10 \%$ \\
\hline $01 / 02 / 2010$ & 110.2094 & 10325.26 & $2.60 \%$ & $2.60 \%$ \\
\hline $04 / 01 / 2010$ & 105.6029 & 10067.33 & $-3.50 \%$ & $-3.50 \%$ \\
\hline $01 / 12 / 2009$ & 112.9457 & 10428.05 & $0.80 \%$ & $0.80 \%$ \\
\hline $02 / 11 / 2009$ & 109.0198 & 10344.84 & $6.50 \%$ & $6.50 \%$ \\
\hline $01 / 10 / 2009$ & 103.6021 & 9712.73 & $0.00 \%$ & $0.00 \%$ \\
\hline $01 / 09 / 2009$ & 102.7431 & 9712.28 & $2.30 \%$ & $2.30 \%$ \\
\hline 03/08/2009 & 101.4031 & 9496.28 & $3.50 \%$ & $3.50 \%$ \\
\hline $01 / 07 / 2009$ & 100.8298 & 9171.61 & $8.60 \%$ & $8.60 \%$ \\
\hline $01 / 06 / 2009$ & 89.27876 & 8447 & $-0.60 \%$ & $-0.60 \%$ \\
\hline $01 / 05 / 2009$ & 90.86905 & 8500.33 & $4.10 \%$ & $4.10 \%$ \\
\hline $01 / 04 / 2009$ & 87.78569 & 8168.12 & $7.30 \%$ & $7.30 \%$ \\
\hline $02 / 03 / 2009$ & 82.41019 & 7608.92 & $7.70 \%$ & $7.70 \%$ \\
\hline $02 / 02 / 2009$ & 78.2765 & 7062.93 & $-11.70 \%$ & $-11.70 \%$ \\
\hline $02 / 01 / 2009$ & 77.5315 & 8000.86 & $-8.80 \%$ & $-8.80 \%$ \\
\hline $01 / 12 / 2008$ & 71.19533 & 8776.39 & $-0.60 \%$ & $-0.60 \%$ \\
\hline 03/11/2008 & 69.02969 & 8829.04 & $-5.30 \%$ & $-5.30 \%$ \\
\hline $01 / 10 / 2008$ & 78.21094 & 9325.01 & $-14.10 \%$ & $-14.10 \%$ \\
\hline $02 / 09 / 2008$ & 98.3925 & 10850.66 & $-6.00 \%$ & $-6.00 \%$ \\
\hline $01 / 08 / 2008$ & 102.4053 & 11543.96 & $1.50 \%$ & $1.50 \%$ \\
\hline $01 / 07 / 2008$ & 107.2454 & 11378.02 & $0.20 \%$ & $0.20 \%$ \\
\hline $02 / 06 / 2008$ & 99.32639 & 11350.01 & $-10.20 \%$ & $-10.20 \%$ \\
\hline $01 / 05 / 2008$ & 108.4604 & 12638.32 & $-1.40 \%$ & $-1.40 \%$ \\
\hline $01 / 04 / 2008$ & 100.7331 & 12820.13 & $4.50 \%$ & $4.50 \%$ \\
\hline 03/03/2008 & 96.09283 & 12262.89 & $0.00 \%$ & $0.00 \%$ \\
\hline $01 / 02 / 2008$ & 95.02457 & 12266.39 & $-3.00 \%$ & $-3.00 \%$ \\
\hline $02 / 01 / 2008$ & 89.05072 & 12650.36 & $-4.60 \%$ & $-4.60 \%$ \\
\hline 03/12/2007 & 89.8738 & 13264.82 & $-0.80 \%$ & $-0.80 \%$ \\
\hline 01/11/2007 & 87.44613 & 13371.72 & $-4.00 \%$ & $-4.00 \%$ \\
\hline 01/10/2007 & 96.20036 & 13930.01 & $0.20 \%$ & $0.20 \%$ \\
\hline $04 / 09 / 2007$ & 97.59217 & 13895.63 & $4.00 \%$ & $4.00 \%$ \\
\hline 01/08/2007 & 96.67259 & 13357.74 & $1.10 \%$ & $1.10 \%$ \\
\hline 02/07/2007 & 91.34573 & 13211.99 & $-1.50 \%$ & $-1.50 \%$ \\
\hline
\end{tabular}




\begin{tabular}{|c|c|c|c|c|}
\hline Date & $\begin{array}{l}\text { PRICE } \\
\text { IBM }\end{array}$ & $\begin{array}{l}\text { PRICE } \\
\text { DOW J }\end{array}$ & $\begin{array}{l}\text { RETURN } \\
\text { IBM }\end{array}$ & $\begin{array}{r}\text { RETURN. } \\
\text { DOW J }\end{array}$ \\
\hline 01/06/2007 & 86.88783 & 13408.62 & $-1.60 \%$ & $-1.60 \%$ \\
\hline $01 / 05 / 2007$ & 88.0023 & 13627.64 & $4.30 \%$ & $4.30 \%$ \\
\hline $02 / 04 / 2007$ & 84.05103 & 13062.91 & $5.70 \%$ & $5.70 \%$ \\
\hline 01/03/2007 & 77.51345 & 12354.35 & $0.70 \%$ & $0.70 \%$ \\
\hline 01/02/2007 & 76.42796 & 12268.63 & $-2.80 \%$ & $-2.80 \%$ \\
\hline 03/01/2007 & 81.2897 & 12621.69 & $1.30 \%$ & $1.30 \%$ \\
\hline $01 / 12 / 2006$ & 79.64997 & 12463.15 & $2.00 \%$ & $2.00 \%$ \\
\hline $01 / 11 / 2006$ & 75.36207 & 12221.93 & $1.20 \%$ & $1.20 \%$ \\
\hline $02 / 10 / 2006$ & 75.45337 & 12080.73 & $3.40 \%$ & $3.40 \%$ \\
\hline $01 / 09 / 2006$ & 66.96252 & 11679.07 & $2.60 \%$ & $2.60 \%$ \\
\hline $01 / 08 / 2006$ & 66.16982 & 11381.15 & $1.70 \%$ & $1.70 \%$ \\
\hline 03/07/2006 & 63.00924 & 11185.68 & $0.30 \%$ & $0.30 \%$ \\
\hline $01 / 06 / 2006$ & 62.529 & 11150.22 & $-0.20 \%$ & $-0.20 \%$ \\
\hline $01 / 05 / 2006$ & 65.03602 & 11168.31 & $-1.70 \%$ & $-1.70 \%$ \\
\hline 03/04/2006 & 66.78066 & 11367.14 & $2.30 \%$ & $2.30 \%$ \\
\hline 01/03/2006 & 66.8861 & 11109.32 & $1.10 \%$ & $1.10 \%$ \\
\hline $01 / 02 / 2006$ & 65.07748 & 10993.41 & $1.20 \%$ & $1.20 \%$ \\
\hline 03/01/2006 & 65.77204 & 10864.86 & $1.40 \%$ & $1.40 \%$ \\
\hline $01 / 12 / 2005$ & 66.50014 & 10717.5 & $-0.80 \%$ & $-0.80 \%$ \\
\hline $01 / 11 / 2005$ & 71.92047 & 10805.87 & $3.50 \%$ & $3.50 \%$ \\
\hline 03/10/2005 & 66.0828 & 10440.07 & $-1.20 \%$ & $-1.20 \%$ \\
\hline $01 / 09 / 2005$ & 64.74307 & 10568.7 & $0.80 \%$ & $0.80 \%$ \\
\hline $01 / 08 / 2005$ & 65.0659 & 10481.6 & $-1.50 \%$ & $-1.50 \%$ \\
\hline $01 / 07 / 2005$ & 67.19637 & 10640.91 & $3.60 \%$ & $3.60 \%$ \\
\hline $01 / 06 / 2005$ & 59.74083 & 10274.97 & $-1.80 \%$ & $-1.80 \%$ \\
\hline $02 / 05 / 2005$ & 60.82777 & 10467.48 & $2.70 \%$ & $2.70 \%$ \\
\hline 01/04/2005 & 61.33312 & 10192.51 & $-3.00 \%$ & $-3.00 \%$ \\
\hline $01 / 03 / 2005$ & 73.37812 & 10503.76 & $-2.40 \%$ & $-2.40 \%$ \\
\hline $01 / 02 / 2005$ & 74.34172 & 10766.23 & $2.60 \%$ & $2.60 \%$ \\
\hline 03/01/2005 & 74.8734 & 10489.94 & $-2.70 \%$ & $-2.70 \%$ \\
\hline $01 / 12 / 2004$ & 79.00899 & 10783.01 & $3.40 \%$ & $3.40 \%$ \\
\hline $01 / 11 / 2004$ & 75.5306 & 10428.02 & $4.00 \%$ & $4.00 \%$ \\
\hline 01/10/2004 & 71.79319 & 10027.47 & $-0.50 \%$ & $-0.50 \%$ \\
\hline $01 / 09 / 2004$ & 68.5855 & 10080.27 & $-0.90 \%$ & $-0.90 \%$ \\
\hline $02 / 08 / 2004$ & 67.74558 & 10173.92 & $0.30 \%$ & $0.30 \%$ \\
\hline $01 / 07 / 2004$ & 69.50224 & 10139.71 & $-2.80 \%$ & $-2.80 \%$ \\
\hline $01 / 06 / 2004$ & 70.36433 & 10435.48 & $2.40 \%$ & $2.40 \%$ \\
\hline $03 / 05 / 2004$ & 70.71555 & 10188.45 & $-0.40 \%$ & $-0.40 \%$ \\
\hline $01 / 04 / 2004$ & 70.23789 & 10225.57 & $-1.30 \%$ & $-1.30 \%$ \\
\hline $01 / 03 / 2004$ & 73.16148 & 10357.7 & $-2.10 \%$ & $-2.10 \%$ \\
\hline $02 / 02 / 2004$ & 76.87372 & 10583.92 & $0.90 \%$ & $0.90 \%$ \\
\hline $02 / 01 / 2004$ & 78.92056 & 10488.07 & $0.30 \%$ & $0.30 \%$ \\
\hline $01 / 12 / 2003$ & 73.71114 & 10453.92 & $6.90 \%$ & $6.90 \%$ \\
\hline
\end{tabular}




\begin{tabular}{|c|c|c|c|c|}
\hline Date & $\begin{array}{l}\text { PRICE } \\
\text { IBM }\end{array}$ & $\begin{array}{l}\text { PRICE } \\
\text { DOW J }\end{array}$ & $\begin{array}{l}\text { RETURN } \\
\text { IBM }\end{array}$ & $\begin{array}{r}\text { RETURN. } \\
\text { DOW J }\end{array}$ \\
\hline $03 / 11 / 2003$ & 72.00914 & 9782.46 & $-0.20 \%$ & $-0.20 \%$ \\
\hline $01 / 10 / 2003$ & 71.03742 & 9801.12 & $5.70 \%$ & $5.70 \%$ \\
\hline $02 / 09 / 2003$ & 70.12444 & 9275.06 & $-1.50 \%$ & $-1.50 \%$ \\
\hline $01 / 08 / 2003$ & 65.10704 & 9415.82 & $2.00 \%$ & $2.00 \%$ \\
\hline $01 / 07 / 2003$ & 64.37444 & 9233.8 & $2.80 \%$ & $2.80 \%$ \\
\hline $02 / 06 / 2003$ & 65.36482 & 8985.44 & $1.50 \%$ & $1.50 \%$ \\
\hline $01 / 05 / 2003$ & 69.75416 & 8850.26 & $4.40 \%$ & $4.40 \%$ \\
\hline $01 / 04 / 2003$ & 67.14335 & 8480.09 & $6.10 \%$ & $6.10 \%$ \\
\hline $03 / 03 / 2003$ & 62.02653 & 7992.13 & $1.30 \%$ & $1.30 \%$ \\
\hline $03 / 02 / 2003$ & 61.64692 & 7891.08 & $-2.00 \%$ & $-2.00 \%$ \\
\hline $02 / 01 / 2003$ & 61.72456 & 8053.81 & $-3.50 \%$ & $-3.50 \%$ \\
\hline $02 / 12 / 2002$ & 61.17205 & 8341.63 & $-6.20 \%$ & $-6.20 \%$ \\
\hline $01 / 11 / 2002$ & 68.60741 & 8896.09 & $5.90 \%$ & $5.90 \%$ \\
\hline $01 / 10 / 2002$ & 62.19424 & 8397.03 & $10.60 \%$ & $10.60 \%$ \\
\hline $03 / 09 / 2002$ & 45.94054 & 7591.93 & $-12.40 \%$ & $-12.40 \%$ \\
\hline $01 / 08 / 2002$ & 59.38943 & 8663.5 & $-0.80 \%$ & $-0.80 \%$ \\
\hline $01 / 07 / 2002$ & 55.34332 & 8736.59 & $-5.50 \%$ & $-5.50 \%$ \\
\hline $03 / 06 / 2002$ & 56.60112 & 9243.26 & $-6.90 \%$ & $-6.90 \%$ \\
\hline $01 / 05 / 2002$ & 63.24389 & 9925.25 & $-0.20 \%$ & $-0.20 \%$ \\
\hline $01 / 04 / 2002$ & 65.71686 & 9946.22 & $-4.40 \%$ & $-4.40 \%$ \\
\hline $01 / 03 / 2002$ & 81.59686 & 10403.94 & $2.90 \%$ & $2.90 \%$ \\
\hline $01 / 02 / 2002$ & 76.98351 & 10106.13 & $1.90 \%$ & $1.90 \%$ \\
\hline $02 / 01 / 2002$ & 84.53742 & 9920 & $-1.00 \%$ & $-1.00 \%$ \\
\hline $03 / 12 / 2001$ & 94.77844 & 10021.57 & $1.70 \%$ & $1.70 \%$ \\
\hline $01 / 11 / 2001$ & 90.57076 & 9851.56 & $8.60 \%$ & $8.60 \%$ \\
\hline $01 / 10 / 2001$ & 84.5741 & 9075.14 & $2.60 \%$ & $2.60 \%$ \\
\hline $04 / 09 / 2001$ & 71.77882 & 8847.56 & $-11.10 \%$ & $-11.10 \%$ \\
\hline $01 / 08 / 2001$ & 78.21951 & 9949.75 & $-5.40 \%$ & $-5.40 \%$ \\
\hline $02 / 07 / 2001$ & 82.22742 & 10522.81 & $0.20 \%$ & $0.20 \%$ \\
\hline $01 / 06 / 2001$ & 88.70651 & 10502.4 & $-3.80 \%$ & $-3.80 \%$ \\
\hline $01 / 05 / 2001$ & 87.37787 & 10911.94 & $1.60 \%$ & $1.60 \%$ \\
\hline $02 / 04 / 2001$ & 89.87956 & 10734.97 & $8.70 \%$ & $8.70 \%$ \\
\hline $01 / 03 / 2001$ & 75.07918 & 9878.78 & $-5.90 \%$ & $-5.90 \%$ \\
\hline $01 / 02 / 2001$ & 77.98305 & 10495.28 & $-3.60 \%$ & $-3.60 \%$ \\
\hline $02 / 01 / 2001$ & 87.32892 & 10887.36 & $0.90 \%$ & $0.90 \%$ \\
\hline $01 / 12 / 2000$ & 66.27641 & 10787.99 & $3.60 \%$ & $3.60 \%$ \\
\hline $01 / 11 / 2000$ & 72.90405 & 10414.49 & $-5.10 \%$ & $-5.10 \%$ \\
\hline $02 / 10 / 2000$ & 76.70507 & 10971.14 & $3.00 \%$ & $3.00 \%$ \\
\hline $01 / 09 / 2000$ & 87.70466 & 10650.92 & $-5.00 \%$ & $-5.00 \%$ \\
\hline $01 / 08 / 2000$ & 102.8048 & 11215.1 & $6.60 \%$ & $6.60 \%$ \\
\hline 03/07/2000 & 87.31493 & 10521.98 & $0.70 \%$ & $0.70 \%$ \\
\hline $01 / 06 / 2000$ & 85.22443 & 10447.89 & $-0.70 \%$ & $-0.70 \%$ \\
\hline $01 / 05 / 2000$ & 83.47424 & 10522.33 & $-2.00 \%$ & $-2.00 \%$ \\
\hline
\end{tabular}




\begin{tabular}{|c|c|c|c|c|}
\hline Date & $\begin{array}{l}\text { PRICE } \\
\text { IBM }\end{array}$ & $\begin{array}{l}\text { PRICE } \\
\text { DOW J }\end{array}$ & $\begin{array}{l}\text { RETURN } \\
\text { IBM }\end{array}$ & $\begin{array}{r}\text { RETURN. } \\
\text { DOW J }\end{array}$ \\
\hline 03/04/2000 & 86.62702 & 10733.91 & $-1.70 \%$ & $-1.70 \%$ \\
\hline $01 / 03 / 2000$ & 91.96838 & 10921.92 & $7.80 \%$ & $7.80 \%$ \\
\hline $01 / 02 / 2000$ & 79.82893 & 10128.31 & $-7.40 \%$ & $-7.40 \%$ \\
\hline $03 / 01 / 2000$ & 87.11801 & 10940.53 & $-4.80 \%$ & $-4.80 \%$ \\
\hline $01 / 12 / 1999$ & 83.72254 & 11497.12 & $5.70 \%$ & $5.70 \%$ \\
\hline 01/11/1999 & 79.98753 & 10877.81 & $1.40 \%$ & $1.40 \%$ \\
\hline 01/10/1999 & 76.15112 & 10729.86 & $3.80 \%$ & $3.80 \%$ \\
\hline 01/09/1999 & 93.78409 & 10336.95 & $-4.50 \%$ & $-4.50 \%$ \\
\hline $02 / 08 / 1999$ & 96.54529 & 10829.28 & $1.60 \%$ & $1.60 \%$ \\
\hline 01/07/1999 & 97.32235 & 10655.15 & $-2.90 \%$ & $-2.90 \%$ \\
\hline $01 / 06 / 1999$ & 100.0809 & 10970.8 & $3.90 \%$ & $3.90 \%$ \\
\hline 03/05/1999 & 89.82113 & 10559.74 & $-2.10 \%$ & $-2.10 \%$ \\
\hline 01/04/1999 & 80.89741 & 10789.04 & $10.20 \%$ & $10.20 \%$ \\
\hline $01 / 03 / 1999$ & 68.54647 & 9786.16 & $5.20 \%$ & $5.20 \%$ \\
\hline 01/02/1999 & 65.64606 & 9306.58 & $-0.60 \%$ & $-0.60 \%$ \\
\hline 04/01/1999 & 70.77288 & 9358.83 & $1.90 \%$ & $1.90 \%$ \\
\hline $01 / 12 / 1998$ & 71.20737 & 9181.43 & $0.70 \%$ & $0.70 \%$ \\
\hline $02 / 11 / 1998$ & 63.77284 & 9116.55 & $6.10 \%$ & $6.10 \%$ \\
\hline $01 / 10 / 1998$ & 57.26743 & 8592.1 & $9.60 \%$ & $9.60 \%$ \\
\hline $01 / 09 / 1998$ & 49.55464 & 7842.62 & $4.00 \%$ & $4.00 \%$ \\
\hline 03/08/1998 & 43.43262 & 7539.07 & $-15.10 \%$ & $-15.10 \%$ \\
\hline 01/07/1998 & 51.00988 & 8883.29 & $-0.80 \%$ & $-0.80 \%$ \\
\hline $01 / 06 / 1998$ & 44.20055 & 8952.02 & $0.60 \%$ & $0.60 \%$ \\
\hline $01 / 05 / 1998$ & 45.23518 & 8899.95 & $-1.80 \%$ & $-1.80 \%$ \\
\hline $01 / 04 / 1998$ & 44.52629 & 9063.37 & $3.00 \%$ & $3.00 \%$ \\
\hline $02 / 03 / 1998$ & 39.91515 & 8799.81 & $3.00 \%$ & $3.00 \%$ \\
\hline $02 / 02 / 1998$ & 40.1313 & 8545.72 & $8.10 \%$ & $8.10 \%$ \\
\hline $02 / 01 / 1998$ & 37.86958 & 7906.5 & $0.00 \%$ & $0.00 \%$ \\
\hline $01 / 12 / 1997$ & 40.12259 & 7908.3 & $1.10 \%$ & $1.10 \%$ \\
\hline 03/11/1997 & 41.9921 & 7823.1 & $5.10 \%$ & $5.10 \%$ \\
\hline 01/10/1997 & 37.70018 & 7442.1 & $-6.30 \%$ & $-6.30 \%$ \\
\hline 02/09/1997 & 40.57076 & 7945.3 & $4.20 \%$ & $4.20 \%$ \\
\hline 01/08/1997 & 38.80057 & 7622.4 & $-7.30 \%$ & $-7.30 \%$ \\
\hline 01/07/1997 & 40.40003 & 8222.6 & $7.20 \%$ & $7.20 \%$ \\
\hline $02 / 06 / 1997$ & 34.47852 & 7672.8 & $4.70 \%$ & $4.70 \%$ \\
\hline 01/05/1997 & 33.04589 & 7331 & $4.60 \%$ & $4.60 \%$ \\
\hline 01/04/1997 & 30.65818 & 7009 & $6.50 \%$ & $6.50 \%$ \\
\hline 03/03/1997 & 26.21704 & 6583.48 & $-4.30 \%$ & $-4.30 \%$ \\
\hline 03/02/1997 & 27.45865 & 6877.74 & $0.90 \%$ & $0.90 \%$ \\
\hline 02/01/1997 & 29.89524 & 6813.09 & $5.70 \%$ & $5.70 \%$ \\
\hline $02 / 12 / 1996$ & 28.87094 & 6448.27 & $-1.10 \%$ & $-1.10 \%$ \\
\hline 01/11/1996 & 30.37166 & 6521.7 & $8.20 \%$ & $8.20 \%$ \\
\hline 01/10/1996 & 24.51712 & 6029.38 & $2.50 \%$ & $2.50 \%$ \\
\hline
\end{tabular}




\begin{tabular}{lrrrr}
\hline \multicolumn{1}{l}{ Date } & \multicolumn{1}{l}{$\begin{array}{l}\text { PRICE } \\
\text { IBM }\end{array}$} & $\begin{array}{l}\text { PRICE } \\
\text { DOW J }\end{array}$ & \multicolumn{1}{l}{$\begin{array}{l}\text { RETURN } \\
\text { IBM }\end{array}$} & $\begin{array}{r}\text { RETURN. } \\
\text { DOW J }\end{array}$ \\
\hline $\mathbf{0 3 / 0 9 / 1 9 9 6}$ & 23.66187 & 5882.17 & $4.70 \%$ & $4.70 \%$ \\
$\mathbf{0 1 / 0 8 / 1 9 9 6}$ & 21.73756 & 5616.21 & $1.60 \%$ & $1.60 \%$ \\
$\mathbf{0 1 / 0 7 / 1 9 9 6}$ & 20.3657 & 5528.91 & $-2.20 \%$ & $-2.20 \%$ \\
$\mathbf{0 3 / 0 6 / 1 9 9 6}$ & 18.75539 & 5654.63 & $0.20 \%$ & $0.20 \%$ \\
$\mathbf{0 1 / 0 5 / 1 9 9 6}$ & 20.22362 & 5643.18 & $1.30 \%$ & $1.30 \%$ \\
$\mathbf{0 1 / 0 4 / 1 9 9 6}$ & 20.34558 & 5569.08 & $-0.30 \%$ & $-0.30 \%$ \\
$\mathbf{0 1 / 0 3 / 1 9 9 6}$ & 21.00646 & 5587.14 & $1.90 \%$ & $1.90 \%$ \\
$\mathbf{0 1 / 0 2 / 1 9 9 6}$ & 23.15431 & 5485.62 & $1.70 \%$ & $1.70 \%$ \\
$\mathbf{0 2 / 0 1 / 1 9 9 6}$ & 20.44256 & 5395.3 & & \#DIV/0! \\
\hline
\end{tabular}

(Authors computation: Monthly returns on stock prices of IBM stocks and the Dow Jones index)

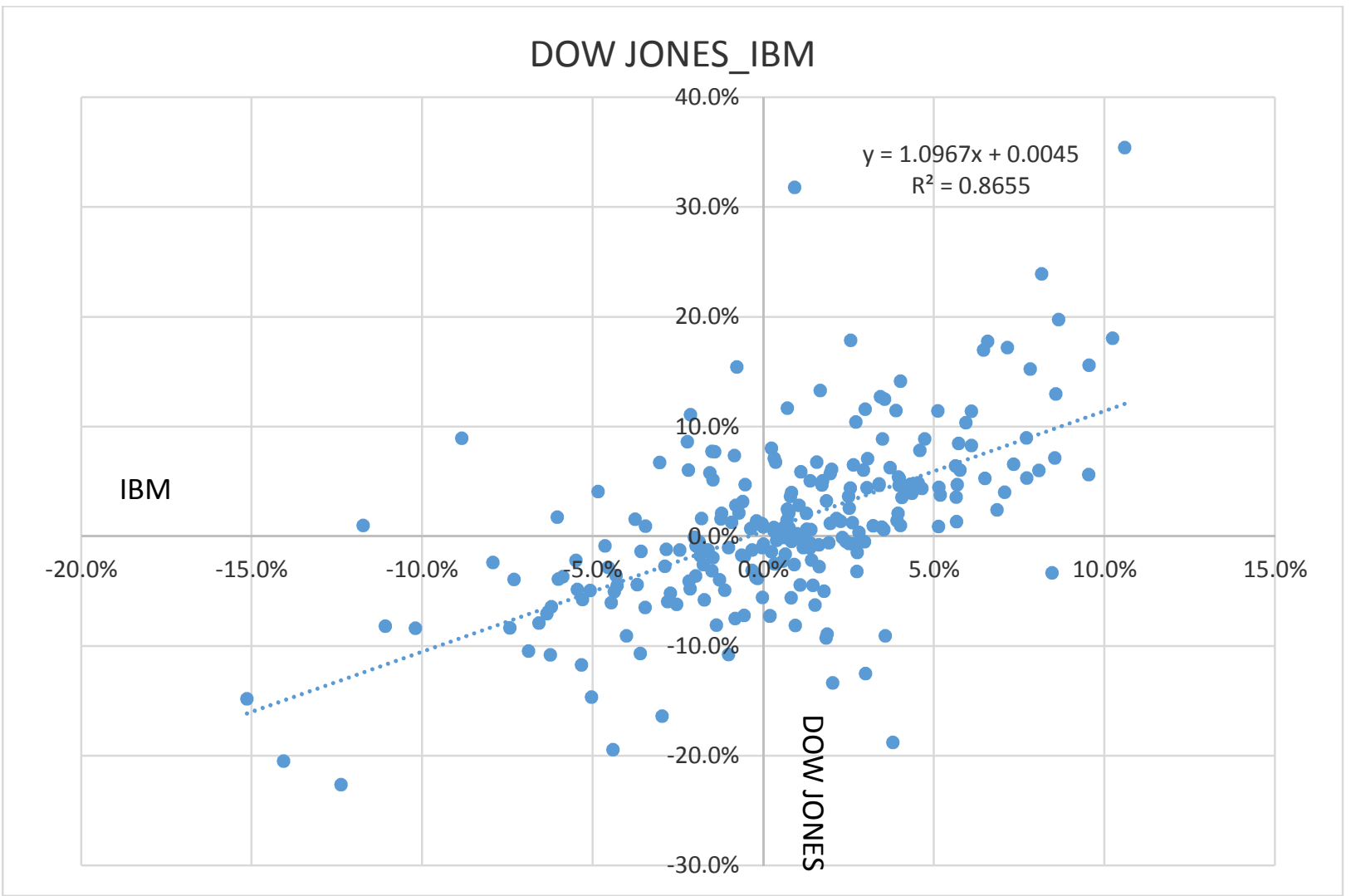

Figure 4: Liner Regression Chart

Figure 4 shows linear regression analysis for the monthly stock returns of Dow Jones and IBM from 1996-2015. The regression analysis revealed that $\mathbf{y}=\mathbf{1 . 0 9 6 7} \mathbf{x}+\mathbf{0 . 0 0 4 5}$. This implies that for every increase in 1 unit of Dow Jones returns; there is a 1.0967-unit increase in the returns for IBM this also refers to the slope of the line.

The $\mathrm{R}^{2}=0.8655$ implies that about $87 \%$ of the variation in IBM returns can be explained by the fluctuations in the Dow Jones returns.

In summary as the Dow Jones stock returns increases, IBM stock returns also increases but with a close or smaller variations. It can therefore be concluded that there is a positive relationship between IBM stock returns and the Dow jones index. 
Table 2

\begin{tabular}{|c|l|}
\hline $\begin{array}{c}\text { Average: Dow-Jones } \\
\text { IBM }\end{array}$ & $0.6 \%$ \\
\hline Variance: Dow-Jones & $1.1 \%$ \\
IBM & 0.00184806 \\
IBM & 0.006082 \\
\hline Std-Devn: Dow-Jones & $4 \%$ \\
Covariance & $8 \%$ \\
\hline Correlation & 0.002026849 \\
\hline Beta & $60 \%$ \\
\hline Slope & 1.10 \\
\hline Aurt & 1.10 \\
\hline
\end{tabular}

Authours Computations

\section{Conclusion}

From the analysis it can be said that there is a positive relationship between a stock and an index thus IBM stocks and the Dow Jones index.

There are many factors which can have a significant effect on the returns of a particular stock which includes the micro and macro demand and supply forces e.g. Industrial capitalization, corporate governance, political shocks etc.

Investors and policy makers must consider some of these forces that affect stock returns before making any decision as far as returns on equities are concerned. There should investor are advised to hold a diversified portfolio in other to avoid shocks that will arise from ROI failures.

\section{References}

Bofah K. (1989). Portfolio theory explained. Retrieved on 12/06/17 from http://www.ehow.com/about 5436842 potfolio theory explain.html

Edwin JE, Martin JG (1997). Modern Portfolio Theory, 1950 to date. J Bank. Fin., 21:1743-1759

Fabozzi F, Gupta, F., \& Markowitz, H. (2002). The legacy of modern portfolio theory, journal of investment, 49, 2, 63-77.

Iyiola O, Munirat Y, \& Nwufo C (2012). The Modern Portfolio Throey as an investment decision tool. Journal of Accounting and Txation Vol. 4(2), pp 19-28.

McClure B. (2010). Modern Portfolio theory: why it's still hip, Investopedia, retrieve $\quad$ on $\quad 02 / 01 / 17$ from http://www.investorpedia.com/articles/06/MPT. aspNaxzz1g3jqy7ny.

Magginson W. (1996). A historical overview of research in finance. Journal of finance, 39,2,323-346. Royal Swedish Academy of Science. (1990). This year's laureates pioneers in the theory of financial economic and cooperate finance. Retrieve on 07/06/16 from http://www.nobelprize.org/nobel_prizes/economic

Tobin J. (1958). Liquidity preference as behaviour toward risk review of economic studies, 65-85

Taleb NN (2007). The Black Swan. The Impact of the Highly Improbable, Random House. Pp 80-120

Veneeya, V. (2006). Analysis of modern portfolio theory.coursework4you. Retrieve on 12/06/16 from http://www.articlebase.com/finance-article/analysis-ofmodern-portfolio-theory-40421.html.

Taleb NN (2007). The Black Swan: The Impact of the Highly Improbable, Random House, pp. 80-120.

First Author: Tan ZhongMing is a Professor for the school of Applied Economics of Jiangsu University in China. He holds a doctoral degree in Management Science \& Engineering from Jiangsu University. His areas of research includes Commercial Bank Management, Credit Management and Corporate Financing, Insurance Policy and Risk Management

The first paragraph may contain a place and/or date of birth (list place, then date). Next, the author's educational background is listed. The degrees should be listed with type of degree in what field, which institution, city, state, and country, and year degree was earned. The author's major field of study should be lower-cased

Second Author: Prince Koomson was born in Ghana in the year 1989 in the western region. He holds a Bachelor in Business Education (B.ed Business) degree from the University for Development Studies UDS in Ghana, Wa campus and was awarded this certificate in 2014. Currently he is a Masters student in Jiangsu University in China reading Applied Economics with stocks and investment banking as his research field.

Third Author: Dr. Ding Guoping is currently a lecturer as the department of Finance and Applied Economics of Jiangsu University in China. 